\title{
$\mathrm{MTF}$ 메시지와 XML간 상호변환 규칙 설계 및 구현
}

\author{
박 인 $\hat{\Upsilon}^{+} \cdot$ 윤 희 병 ${ }^{++}$
}

요 약

\begin{abstract}
MTF 메시지는 CAI 체계와 같은 국방 메시지 시스템에서 필요한 정보를 상호 교환하거나 다른 시스템으로 정보를 전달하고자 할 때 사용되 는 정형화되고 표준화된 메시지 포맷이며, XML은 다양한 검색 지원 및 하드웨어나 소프트웨어에 종속되지 않는 장점을 바탕으로 인터넷 기반 에서 전자정보의 효율적 표현과 교환에 최적의 수단으로 평가 받고 있다. 미군은 MTF에 이러한 XML 기반 기술과 결합한 XML-MTF를 도입 하여 지속적인 개량과 발전을 도모하고 있으나, 우리 군은 자체 MTF 체계를 보유하지 않고 있으며 또한, 여러 CAI 체계가 Web 기반으로 이 동함에 따라 한.미간 효율적인 연합작전 수행을 위해 MTF의 필요성이 증가하고 있다.

본 논문에서는 MTF 매시지의 기본구조 및 본문 구성, 작성규칙을 분석하며, 이러한 결과를 바탕으로 XML 변환을 위한 엘리먼트 명칭과 기본적인 매핑(Mapping) 규칙을 제안한다. 또한, 제안된 매핑 규칙을 적용하여 MTF 메시지 샘플을 XML 문서로 직접 변환해 봄으로써 MTF 메시지가 XML 문서로 변환이 가능함을 보이고, 이를 기반으로 MTF 메시지를 생성하고 이를 자동으로 XML 문서로 변환하는 XML-MTF 변 환 프로그램을 구현한다.
\end{abstract}

키워드 : MTF(Message Text Format), XML(Extensible Mark-up Language), XML-MTF, 매핑 규칙

\section{Design and Implementation of the Conversion Rule between XML and MTF Messages}

\author{
InSoo Park ${ }^{+} \cdot$ Heebyung Yoon ${ }^{++}$
}

\begin{abstract}
MTF message is the normalized and standardized format which is used in the time when it tries to transmit data to other systems or exchanges needed information in defense message systems. XML can support variety of search functionality and is estimated to be the best way from the view of efficient presentation and exchange in internet based environment, based on advantage which is independent of hardware and software. US army brought in XML-MTF combining with XML based technology, but we do not contain such a MTF system, and necessity of MTF is increasing for combined operation between ROK and US as a lot of C4I system were transferred to Web based systems.

In this paper, we make analysis of fundamental structure, organization of paragraph, witting regulation of MTF message. We present the rule of naming element and fundamental mapping rule for transformation of its XML based on it. Also, we prove that MTF message can be transformed to XML document by trying to transforming sample documents to XML document applying presented mapping rule, creating MTF message based on it and implement program which can automatically transform them to XML-MTF.
\end{abstract}

Key Words: MTF(Message Text Format), XML(Extensible Mark-up Language), XML-MTF, Mapping Rule

\section{1. 서 론}

최근 전쟁의 양상은 정보위성 및 무인항공기 등의 정밀감 시체계를 이용하여 군사목표를 정찰하고, 판독된 목표지점 에 정밀 유도탄을 발사함으로써 지하부터 고산지대까지 목 표를 무력화 시킬 수 있으며, 공격후 적의 피해 정도를 판 독, 분석하여 차기 공격에 반영하는 고도의 정보전 중심으 로 이동하고 있다[1]. 이러한 정보전을 수행하는 중심적인

† 정 회 원 : 공군 전투비행단 무잠대대

+ 종신회원 : 국방대학교 전산정보학과 조교수

논문접수 : 2005 년 4월 12 일, 심사완료 : 2005 년 5월 19일
역할을 수행하는 것이 C4I 시스템이라 할 수 있으며, 우리 군도 첨단 정보체계 구축을 목표로 일부는 체계를 개발하여 사용 중에 있거나 개발 중에 있다.

$\mathrm{MTF}$ 메시지는 이러한 $\mathrm{CAI}$ 시스템의 프로세스에서 전술 정보가 분석 및 합성되는 과정에서 필요한 정보를 상호 교 환하거나 다른 시스템으로 전술정보를 전달하고자 할 때, 결심한 사항을 지시 또는 하달할 때 사용되는 정형화된 메 시지 포맷이다[2].

한편, 정보화 사회가 발전함에 따라 $\mathrm{Web}$ 기반 환궁에서 급격히 늘어나는 전자정보의 효율적 표현과 교환을 위해 $\mathrm{XML}$ 관련 기술이 인터넷 기반의 많은 응용분야에 적용되 
고 있다 $[3,4]$. 미군은 오랫동안 사용해온 $\mathrm{MTF}$ 메시지를 $\mathrm{XML}$ 기반의 XML-MTF로 발전시켜 미군 $\mathrm{CAI}$ 시스템인 $\mathrm{GCCS}$ 시스템간 전술정보 공유에 사용하는 등 지속적인 개 량과 발전을 이룩하고 있다 $[5,6,7]$.

우리 군의 경우 자체 $\mathrm{MTF}$ 체계는 보유하고 있지 않다. 게다가 $\mathrm{MTF}$ 메시지의 구조와 내용에 대한 구체적인 연구 사례가 미비하고, 현재 미군에서 사용 중인 XML-MTF에 대해서는 일부 개념적인 내용 이외의 자세한 자료는 공개되 지 않고 있어 $\mathrm{MTF}$ 메시지에 대한 분석과 MTF 메시지의 $\mathrm{XML}$ 변환 연구에 대한 관심이 증가되고 있다. 따라서 본 논문에서는 $\mathrm{MTF}$ 메시지를 생성하여 이를 XML 문서로 변 환하고, 이를 다시 MTF 매시지로 변환하는 프로그램을 구 현한다. 이를 위해 먼저 MTF 메시지의 기본구조 및 본문 구성, 작성규칙에 대해 분석하고, 분석된 $\mathrm{MTF}$ 메시지 구조 를 바탕으로 $\mathrm{XML}-\mathrm{MTF}$ 변환을 위한 $\mathrm{MTF}$ 와 $\mathrm{XML}$ 과의 매 핑(mapping) 규칙을 제안한다. 또한, 제안된 매핑 규칙을 적 용하여 MTF 메시지 샘플을 XML 문서로 직접 변환해보며, 메시지별 엘리먼트 명칭과 속성을 정의하는 스키마 파일을 작성한다.

\section{MTF(Message Text Format)}

\subsection{MTF 개요}

지휘통제시스템에 있어 정보의 교환은 모든 국방조직의 기본적인 활동이다. 이러한 정보들이 적시에, 정확하게, 간결 하게, 이해 가능토록 전달되기 위해 별도의 전용 언어 (language)가 필요하게 되었다. MTF는 이러한 필요성에 따 라 C4I 시스템간 정보를 전달하기 위한 매체로서 표준화된 메시지 포맷을 확실히 구축하기 위한 규칙, 구조, 어휘가 포 함된 언어이다[8].

미군은 사람이 인식할 수 있을 뿐만 아니라 기계에서도 처리 가능한 메시지를 작성하고, 메시지 기안, 전송, 분석, 해석, 처리에 필요한 시간과 노력을 절감하며, 사용되는 용 어를 통일함으로써 정보교환 효율을 향상시키고, 모든 전술 상황에서 사용될 특정 보고절차를 제공하며, 미국과 동맹국 간 용이한 정보교환 환경을 제공하기 위해 오래전부터 MTF를 제정하여 사용해오고 있다.

한 - 미간에도 연합작전에 사용되는 몇 개의 MTF 메시지 를 선정하였으며, 이에 관한 내용을 “한 - 미 표준전문양식 (ROK/US MTF) 연합상호연동운용절차(CIOP) 사용자 교 범"에 수록하여 발간하였다[9]. 이 교범에는 MTF 작성을 위한 기본규칙, 각 메시지를 구성하는 Set, Set을 구성하는 필드(field) 등이 정의되어 있다.

\subsection{MTF 구성요소}

$\mathrm{MTF}$ 의 기본구조는 자연어 구조와 유사한데, $\mathrm{MTF}$ 를 구 성하는 필드(field), Set, 메시지(message)는 자연어에서 단 어(word), 문장(sentence), 본문(text)이라 할 수 있다. 즉, 자 연어의 본문이 단어와 문장으로 구성되는 것처럼 $\mathrm{MTF}$ 에서

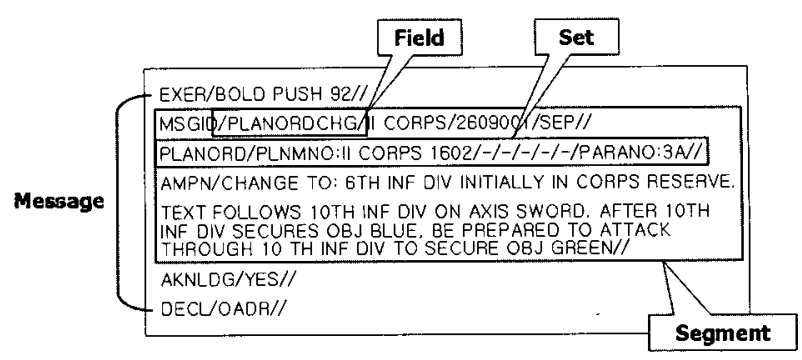

(그림 1) 메시지, 세그먼트, Set, 필드의 관계

도 자연어와 같은 방법으로 필드와 Set으로 이루어진다.

$\mathrm{MTF}$ 를 구성하는 3가지 요소인 필드, Set, 메시지는 최하 위 레벨인 필드 $\rightarrow$ Set $\rightarrow$ 메시지 순으로 구성될 수 있으며, 2개 이상의 Set들의 집합을 세그먼트라고 한다. Set은 하나 또는 여러 개의 필드로 구성되며, Set 명칭은 다른 모든 Set 과 구별되고 기억하기 쉬운 유일한 명칭을 사용한다. 필드 는 Set을 이루는 가장 하위 단위로서 문자 또는 특정 코드 를 사용하여 위치, 이름과 같은 단일 개념 또는 날짜-시간 그룹 같은 복합 개념을 표현한다. 메시지, 세그먼트, Set, 필 드의 개념적인 관계를 (그림 1)에 도시하였다.

\subsection{MTF 작성규칙}

MTF 작성에는 표준 알파벳 문자 및 숫자를 사용한 필드 로 이루어진 Set을 사용하며, 사용되는 기호와 기능의 사용 에는 다소 제한이 있다. 즉, 각 필드마다 허용되는 문자는 필드의 성격에 따라 서로 상이하다. 예를 들어, 숫자만 허용 되거나, 문자만 허용되는 필드가 있으며, 모든 문자를 사용 할 수 있으나 길이가 제한되는 필드가 있다. 또한, MTF에 는 특수 목적을 가진 기호가 사용되는데 (그림 2)에 특수기 호의 종류 및 위치를 나타내었다.

필드표시자(field marker)로 사용되는 슬래쉬(/)는 필드의 시작을 나타내고, Set 종료표시자(end-of-Set marker)는 이 중 슬래쉬 $(/ /)$ 로 표시하며, Set을 종료하는 마침표로서의 역 할을 수행한다. 콜론(:)은 필드묘사자 한정(field descriptor delimiter)으로 사용되며, 필드내용에 추가되는 사항을 기록 할 때 사용한다. 하이픈(-)은 무자료기호로 펼드내용에 데이 터가 존재하지 않을 때 자료가 없음을 표시한다.

$\mathrm{MTF}$ 작성규칙은 문장 작성방법과 마찬가지로 왼쪽에서 오른쪽으로 행을 만들어 나간다. 왼쪽 여백에서 Set 명칭으 로 시작하여 왼쪽에서 오른쪽으로 각 필드가 시작되며, Set 종료표시자로 Set이 종료된다. 또한, MTF 메시지는 매 행 마다 최대 69문자만 허용된다. Set이 길어져서 69문자를 초 과해야 한다면 행을 바꾸어 계속적으로 작성해나가야 한다.

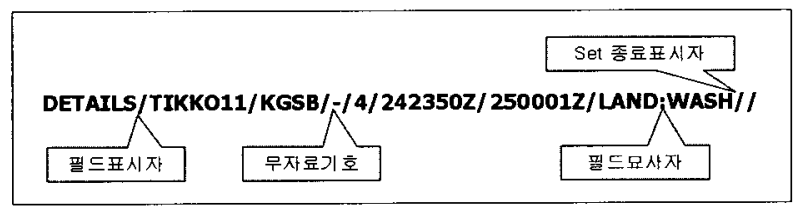

(그림 2) 특수기호의 종류 및 위치 


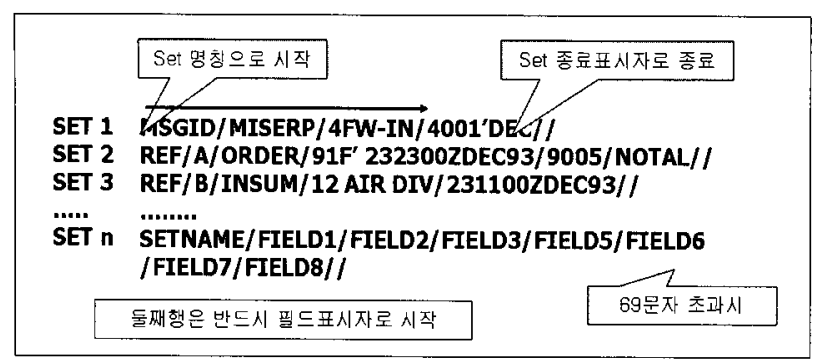

(그림 3) MTF 일반 작성규칙

이러한 기본적인 MTF 메시지 작성규칙을 (그림 3)에 나타 내었다.

각각의 Set에는 필수필드(mandatory fields)와 선택필드 (operationally determined fields)가 있다. 필수필드는 Set이 사용된다면 반드시 입력되어야하는 필드이고, 선택필드는 상황에 따라 입력될 필요가 있을 때 입력되는 필드이다. 필 수필드에는 입력되는 정보가 없을 때 무자로기호(-)를 사용 하여 데이터가 없음을 기록해야하지만 선택필드의 경우에는 생략이 가능하다.

자유-텍스트(Free-text) Set은 사용하는 문자나 길이에 제한을 받지 않고 원하는 내용을 기록할 수 있는 Set이다. 즉, 일반 Set을 사용하기에는 Set의 형태가 부적절하거나 세 부사항에 대한 추가가 용이하지 않을 경우, 주의가 요망되 는 정보 또는 소멸된 정보를 강조할 경우, 메시지에 적절한 정보를 추가하기 위해 사용된다.

\section{XML-MTF 매핑규칙 및 스키마 작성}

\subsection{MTF 구조 분석}

MTF 메시지 체계는 각각의 메시지가 정의되어 있고, 각 메시지는 Set을 가지고 있으며, 각 Set은 일정한 규칙의 필 드로 구성되어 있다. 따라서 전체적으로 메시지 체계는 (그 림 4)와 같이 트리형식의 계층적 구조임을 알 수 있다[10]. 또한, MTF 메시지 작성시 필요한 상황 또는 전송하고자하 는 내용에 따라 전체 메시지 중에서 적절한 메시지를 선택 하여 사용하게 된다. 따라서 각 메시지는 각자 고유의 내용 을 가지고 독립적으로 사용되므로 각 메시지별로 $\mathrm{XML}-$ $\mathrm{MTF}$ 가 생성되어야 하며, 메시지별 특성을 반영한 각각의 $\mathrm{XML}$ 문서를 정의해야 한다.

각 메시지에 사용되는 Set은 메시지의 의미를 완성하는데 필요한 최상위 단위라 할 수 있다. 이러한 Set 들의 조합으 로 하나의 메시지가 완성되므로 이를 XML로 변환하기 위 해서는 각 Set의 이름을 기본 엘리먼트로 정의할 필요가 있 다. 또한, 필드는 Set을 구성하는 하위단위이며, 메시지를 구 성하는 최하위 단위이다. 그러므로 XML로 변환하기 위해서 는 우선 필드에 입력되는 데이터의 속성을 고려하여 필드명 칭이 정의되어야 하며, 정의된 필드명칭을 바탕으로 변환될 $\mathrm{XML}$ 문서의 엘리먼트 명칭을 정의해야 한다. 정해진 엘리 먼트 명칭에는 필드별 속성을 고려하여 엘리먼트의 속성을

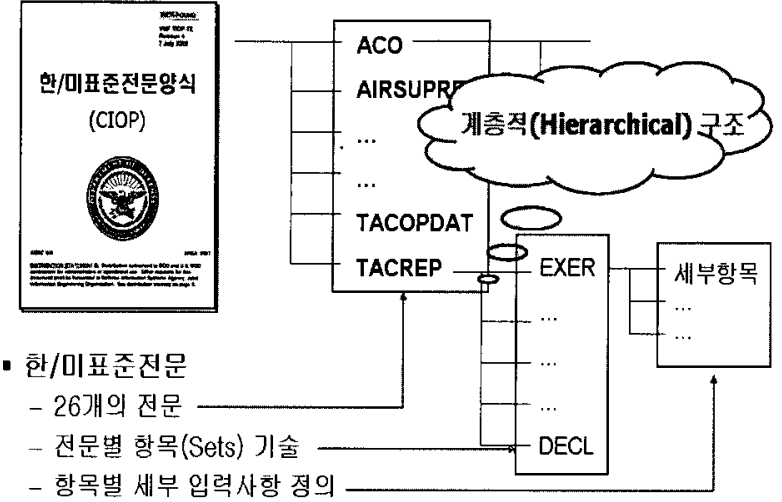

(그림 4) MTF 메시지 체계

각각 지정해주어야 한다. XML 변환시 생성되는 메시지별로 일일이 속성을 지정하는 것은 비합리적이므로 메시지별 별 도의 스키마 문서를 작성할 필요가 있다.

\section{$3.2 \mathrm{XML}-\mathrm{MTF}$ 매핑 규칙}

XML-MTF 매핑은 주어진 MTF 메시지를 XML 문서로 포현하는 방법이라 할 수 있다. 즉, XML-MTF 매핑은 MTF 메시지의 내용을 손상 없이 XML-MTF 엘리먼트와 $\mathrm{MTF}$ 메시지 구성요소들 간의 관계를 표현하는 것이 관건 이다.

XML-MTF 메시지의 루트 엘리먼트는 MTF 메시지 명 칭과 대응될 수 있으며, 메시지가 Set들로 구성된 것처럼 루 트 엘리먼트 이하에는 Set 명칭과 대응되는 자식(child) 엘 리먼트로 구성된다. 또한, MTF 메시지의 구성요소인 세그 먼트, Set, 필드는 XML-MTF에서는 모두 아래와 같은 $\mathrm{XML}$ 문서의 기본 형태로 변환된다.

<element_name> content </element_name>

따라서 "<element_name>"은 MTF 메시지의 메시지 명칭, Set 명칭, 필드 명칭을 이용하여 결정하여야 하고, "content"는 필드 내용 및 속성을 고려하여 결정되어야 할 것이다.

XML-MTF에서의 엘리먼트 명칭은 MTF 메시지의 구성 요소를 가지고 결정할 수 있으며, 엘리먼트 명칭으로 결정 될 수 있는 요소는 메시지 명칭(MSGID), Set 포맷 식별자, 필드 데이터 등이 될 수 있다. 이러한 요소들은 그대로 엘 리먼트 명칭으로 변경 가능한 것도 있지만 대부분은 $\mathrm{XML}$ 문서 표준에 맞도록 변경할 필요가 있기 때문에 사전 필터 링(filtering) 작업이 필요하다[11]. 예를 들어 $\mathrm{MTF}$ 구성요소 명칭에 공백이나 톡수문자가 포함되어 있을 경우 이를 제거 하거나 다른 문자로 변경해야 하며, 같은 명칭이 존재할 경 우에는 서로 구분할 수 있도록 적당한 다른 명칭으로 변경 하거나 대체해야 한다.

본 논문에서는 엘리먼트 명칭을 결정하기 위하여 다음과 같은 규칙을 설정하였다.

첫째, XML-MTF 엘리먼트 명칭 결정시 메시지 및 Set 
명칭으로 사용할 때는 영문 대문자를 사용하고, 필드 명칭 으로 사용할 때는 영문 소문자를 사용한다.

둘째, XML-MTF 엘리먼트 명칭에는 알파벳 문자와 underline(_)만 사용하는 것으로 한다. 따라서 MTF 메시지에 서 알파벳이 아닌 다른 문자나 공백은 엘리먼트 명칭에서는 아래 예제와 같이 제거하거나 underline(_)으로 변경하여 사 용한다.

예) date(time) $\rightarrow\langle$ date_time $>$ general text info $\rightarrow\langle$ general_text_info $\rangle$

셋째, 만일 하나의 메시지 안에서 엘리먼트 명칭이 중복 되는 경우 엘리먼트 명칭 다음에 번호를 부여하여 서로 구 분하도록 한다. 엘리먼트 명칭 중복은 필드 명칭 매핑시 자 주 나타난다.

$$
\begin{aligned}
\text { 예) date(time) } & \rightarrow<\text { date_time }> \\
\text { date(time) } & \rightarrow<\text { date_time_2 }> \\
\text { date }(\text { time }) & \rightarrow<\text { date_time_3 }>
\end{aligned}
$$

필드 매핑은 필드가 어떤 내용을 나타내는가에 따라 부여 해야 하므로 Set별 필드의 내용을 각각 분석하여 결정해야 한다. 또한, 필드의 용도를 쉽게 알 수 있도록 축약된 용어 는 풀어서 명시하고, 필드의 용도와 의미를 대표할 수 있는 용어를 선택하여야 한다. 필드별로 엘리먼트 명칭을 매핑한 예를 (그림 5)에 나타내었다.

(그림 5)에서 AIROP Set의 첫 번째 필드는 날짜와 시간 을 나타내므로 엘리먼트 명칭을 <Date_time>으로 설정하였 고, 두 번째 필드는 국가를 의미하므로 <country>로 설정하 였다. 세 번째 필드는 항공기 대수를 의미하므로 <Quantity> 로 설정하였다.

Set 매핑은 일반적으로 Set 명칭이 쉅게 알아볼 수 있도 록 되어 있고, 함축된 의미의 약자로 설정되어 있어 인지하 는뎨 별다른 문제점이 없으므로 XML 문서로 변환시 Set 명칭을 변경하지 않고 그대로 엘리먼트 명칭으로 매핑한다. 이러한 Set 명칭 매핑 과정을 (그림 6)에 나타내었다.

메시지 매핑은 메시지 명칭을 그대로 최상의 엘리먼트 명 칭으로 매핑 한다. 즉, (그림 7)과 같이 메시지 명칭은 MSGID Set예 명시되므로, XML 문서 변환시 MSGID Set 을 참조하여 최상위 엘리먼트 명칭으로 매팡 한다.

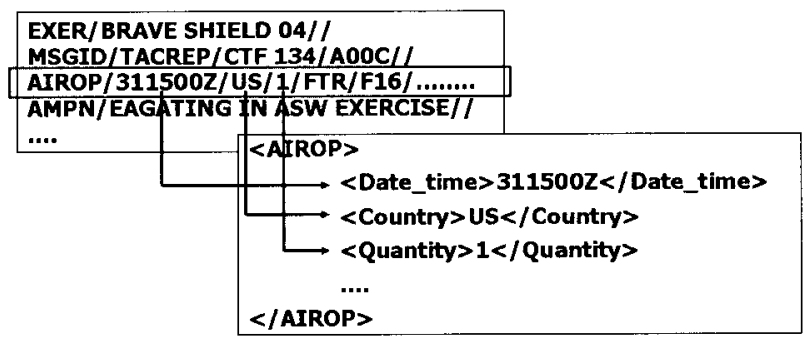

(그림 5) 필드 명칭 매핑

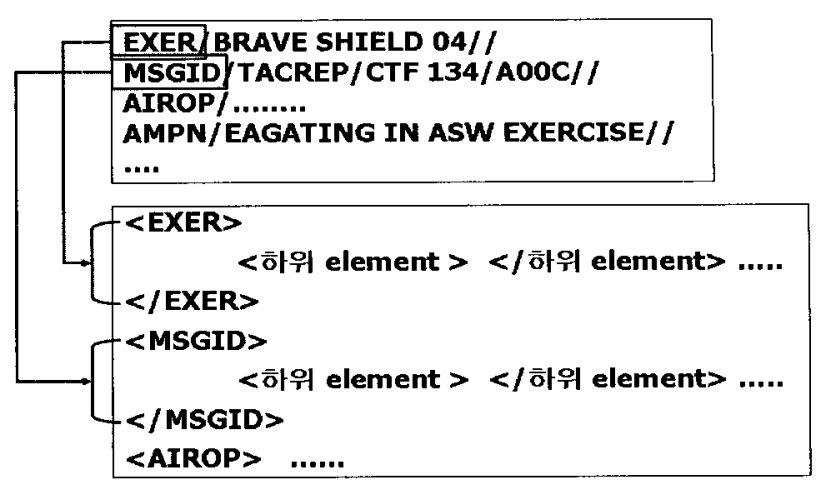

(그림 6) Set 명칭 매핑

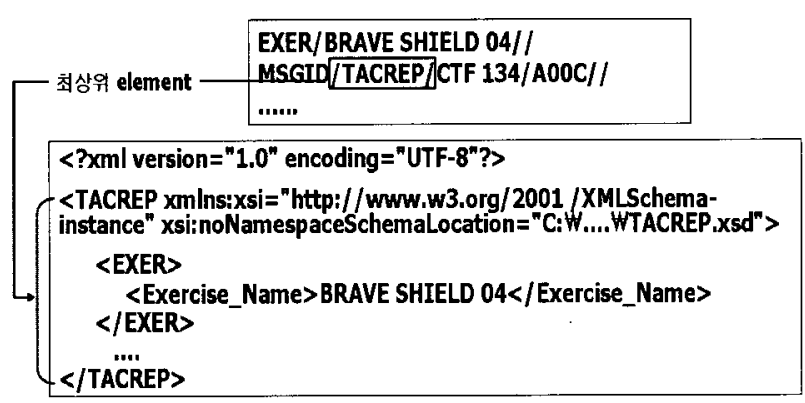

(그림 7) 메시지 매팡

\section{3 매핑규칙 적용}

지금까지 설정한 매퓡 규칙을 바탕으로 실재 $\mathrm{MTF}$ 메시 지를 XML 문서로 변환해 본다.

$\mathrm{MTF}$ 메시지 샘플은 다음과 같다[9].

MSGD/TACREP/CTF 12A//

ACTY/RED SEA MANEUVERS/011700Z//

MAROP/011600Z/1/US/SUB/CL:SKATE/NAME:SEAWOLF

LM:4000N1000E//

MAROP/011800Z/1/US/SUB/CL:WASHINGTONG

NAME:SEAROVER/LM:4040N0110E//

AIROP/020200Z/6/US/FTR/F15/TN:401/LM:4130N0100E

/CRS:180/SPD:600KPH/ALT:12000FT//

AMPN/ENGAGING IN ASW EXERCISE//

$\mathrm{XML}$ 로 변환하기 위하여 먼저 최상위 엘리먼트를 결정한 다. 앞서 설정한 규칙대로 최상위 엘리먼트는 메시지 명칭 을 그대로 적용하므로 아래와 같이 최상위 엘리먼트를 설정 할 수 있다.

\begin{tabular}{|c|}
\hline <TACREP> \\
<하위 엘리먼트> \\
$\cdots \cdots \cdots . .$. \\
</하위 엘리먼트> \\
</TACREP>
\end{tabular}

다음으로 메시지에 사용된 Set은 5 개 이므로 하위 엘리먼 트는 5 개가 생성된다. Set 명칭에 대한 매핑 규칙에 따라 Set 명칭 그대로 엘리먼트 명칭을 설정한다. 따라서 사용된 
메시지와 Set에 대한 최상위 엘리먼트와 하위 엘리먼트는 아래와 같이 설정될 수 있다.

\begin{tabular}{|c|c|}
\hline \multicolumn{2}{|l|}{$\langle$ TACREP $\rangle$} \\
\hline$<$ MSGD $>$ & $\langle/$ MSGD $\rangle$ \\
\hline$<\mathrm{ACTY}\rangle$ & $\cdots \cdots \quad</$ ACTY $>$ \\
\hline$\langle$ MAROP $\rangle$ & $<$ MAROP $>$ \\
\hline$<$ MAROP $>$ & $\ldots \ldots<<$ <MAROP $>$ \\
\hline <AIROP> & $</$ AIROP $\rangle$ \\
\hline$<$ AMPN $>$ & $\cdots \cdots<<$ <AMPN $>$ \\
\hline$\langle/$ TACREP $\rangle$ & \\
\hline
\end{tabular}

마지막으로 필드 명칭을 정의하고 이를 매핑해야 한다. 앞 에서처럼 메시지 명칭과 Set 명칭은 변경함이 없이 사용할 수 있지만, 필드 명칭은 별도로 정해진 것이 없기 때문에 필 드의 용도와 데이터 내용에 따라 정의해 주어야 한다. 이러 한 사항들을 고려하여 필드 명칭을 아래와 같이 정의하였다.

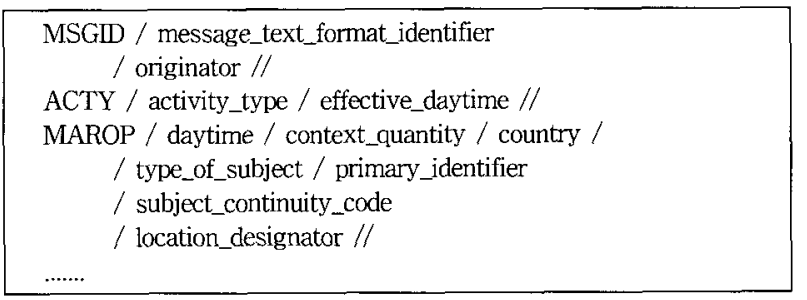

이러한 방법으로 만들어진 XML 문서의 기본 골격에 $\mathrm{MTF}$ 메시지의 내용을 입력하면 최종적으로 다음과 같은 XML-MTF 문서를 생성할 수 있다.

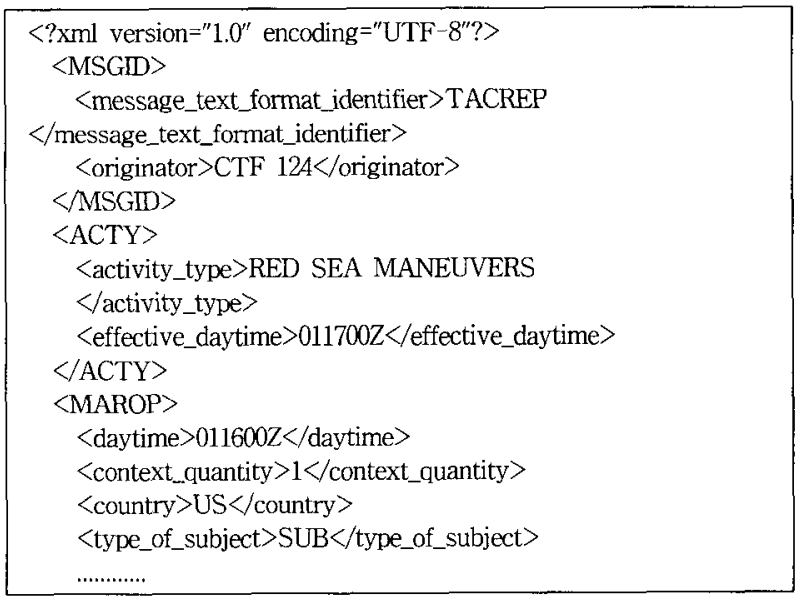

지금과 같은 작업을 통해 $\mathrm{MTF}$ 메시지가 $\mathrm{XML}$ 문서로 변환이 가능함을 알 수 있다. 따라서 이러한 방법으로 모든 $\mathrm{MTF}$ 메시지가 XML 문서로 변환이 가능하다면, XML의 확장성과 활용성을 바탕으로 $\mathrm{MTF}$ 메시지의 응용범위가 크 게 확대될 수 있을 것이다.

$3.4 \mathrm{XML}-\mathrm{MTF}$ 스키마 작성

앞서 기술한 것처럼 $\mathrm{MTF}$ 메시지는 고유의 형식을 가진
필드의 집합으로 이루어진다. 이를 XML 문서로 변환할 때 사용자마다 서로 다른 엘리먼트 명칭으로 지정되어도 XML 문서 자체로는 유효한 문서가 될 수 있지만, 생성되는 $\mathrm{XML}-\mathrm{MTF}$ 문서가 일관성을 유지할 수 없게 된다. 따라서 필드의 성격에 따라 문자, 숫자, 길이 등 입력되는 데이터의 형식을 미리 정의하여 잘못된 데이터 형식이 입력되지 않도 록 해야 한다. 즉, 스키마를 정의함으로써 생성되는 XML$\mathrm{MTF}$ 문서의 유호성을 보장하고, 정의되어 있지 않은 엘리 먼트 명칭이나 속성을 사용하지 못하게 함으로써 데이터의 무결성을 보장할 수 있다[12].

스키마 문서에 정의되는 내용은 XML-MTF 문서의 엘리 먼트 명칭, 엘리먼트별 속성, 엘리먼트 길이, 엘리먼트 데이 터 타입 등이며, 각각의 메시지에 대해 스키마 문서가 생성 되어야 한다. 본 논문에서는 이들 중에서 앞에서 샘플로 구 현한 TACREP 메시지에 대해 스키마 문서인 TACREP.xsd 파일을 작성하였으며, 처음부분의 일부를 <그림 8>에 나타 내었다. 그림에서 보듯이 최상위 엘리먼트로 메시지 명칭인 <TACREP> 엘리먼트를 정의하였고, 메시지를 구성하는 19 개 Set 명칭으로 자식 엘리먼트를 정의하였다.

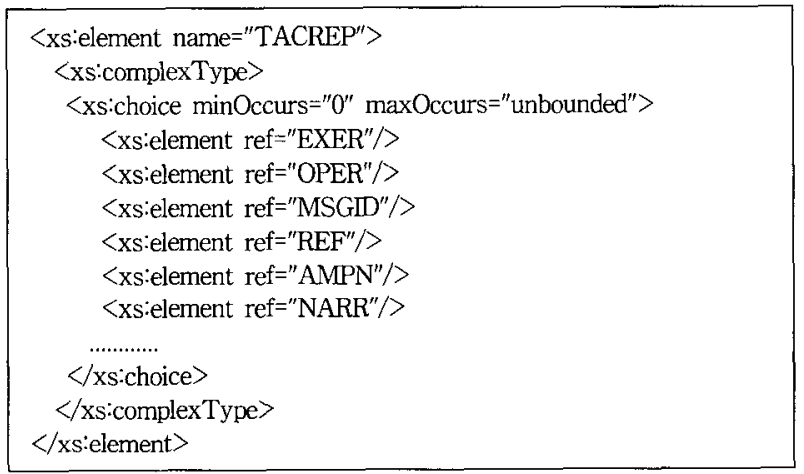

(그림 8) 스키마에서 엘리먼트 명칭 정의

다음으로 Set을 구성하는 필드와 매평되는 엘리먼트 명칭 을 정의하였다. 19개 Set 각각에 대해 필드 엘리먼트 명칭을 정의해야 하며, (그림 9)는 이중에서 AIROP 엘리먼트를 구 성하는 자식 엘리먼트가 나타나 있다. 필드 엘리먼트는 Set 에서 필드가 작성되어야하는 순서대로 나열되어야 하며, 선 택 필드의 경우에는 생략이 가능하므로 "minOccurs="0" maxOccurs="unbounded" 속성을 부여하여 생략이 가능하도 록 정의하였다.

필드 엘리먼트를 정의가 끝나면, 각 필드 엘리먼트의 속 성을 지정해야 한다. 각 필드 엘리먼트별 속성을 지정하는 내용의 일부를 (그림 10)에 나타내었다.

(그림 10)에서 context_quantity 엘리먼트와 quantity 엘 리먼트의 경우 속성이 정수이며, 길이는 제한이 없음을 나 타낸다. date_and_time_of_reference 엘리먼트는 속성이 문자 열이며, 길이는 최소 6 글자에서 최대 13 글자까지 가능함을 나타낸다.

이러한 방법으로 각 $\mathrm{MTF}$ 메시지별 스키마 파일을 작성 


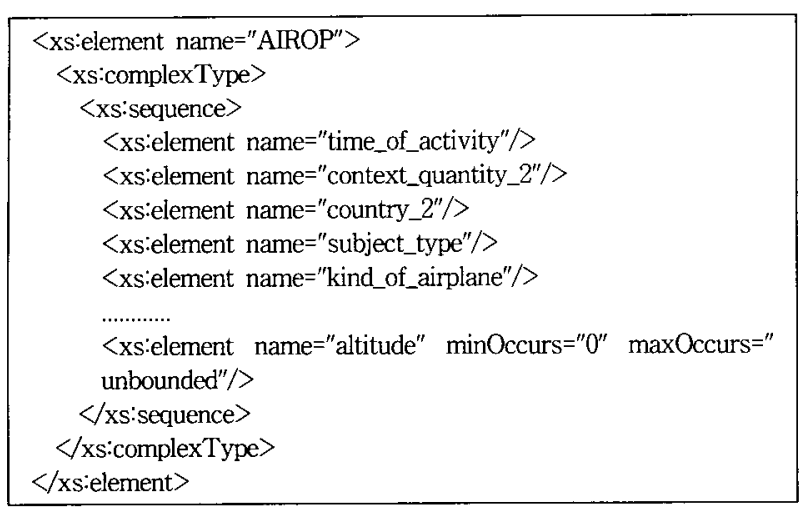

(그림 9) Set올 구성하는 필드 엘리먼트 정의

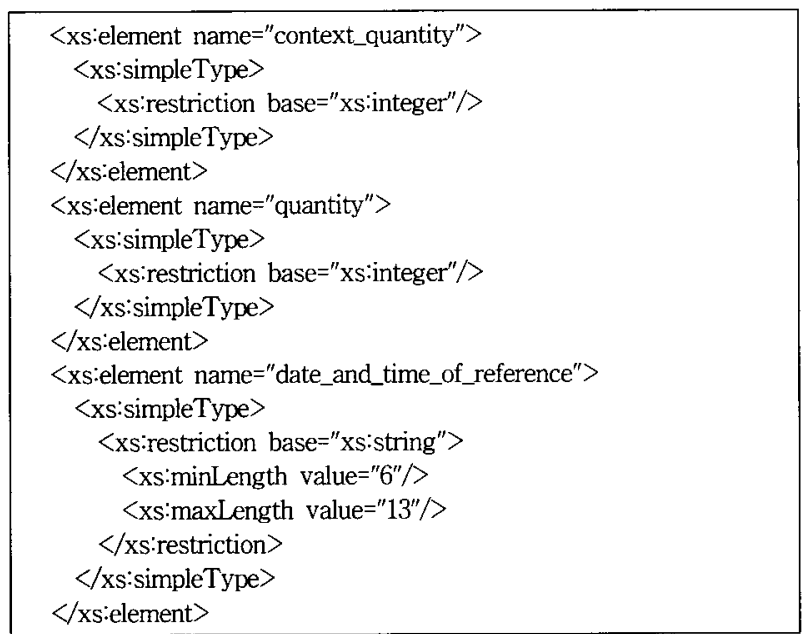

(그림 10) 필드 엘리먼트 속성 정의

해 놓으면, 생성되는 XML-MTF 문서에 대한 유효성 검사 를 통해 정해진 데이터 타입과 엘리먼트 명칭대로 작성되었 는지에 대한 여부를 검사할 수 있고, 잘못된 형식의 문서가 생성되는 것을 예방할 수 있다.

\section{XML-MTF 상호변환 구현}

\section{1 프로그램 구성}

본 논문에서 구현한 XML-MTF 변환 프로그램은 사용자 인터페이스 모듈, 필드 추출기 모듈, 태그 추출기 모듈 등 크게 3 가지 부분으로 되어 구성되어 있다. 사용자 인터페이 스 모듈은 프로그램의 중심부분으로서 MTF 메시지를 쉽게 작성할 수 있도록 MTF 메시지 작성 폼(Form)을 제공하며, 이 폼으로 부터 메시지 필드를 입력받으면 필드를 조합하여 $\mathrm{MTF}$ 메시지를 출력한다. 또한, MTF 메시지를 XML로 변 환하기 위해 MTF 메시지를 필드 추출기 모듈로 보내고 그 결과를 받아 XML 태그를 매핑하여 XML 문서로 출력하거 나, XML 문서를 MTF 메시지로 변환하기 위해 XML 문서 를 태그 추출기 모듈로 보내고 그 결과를 받아 필드를 조합 하여 MTF 문서로 출력한다.

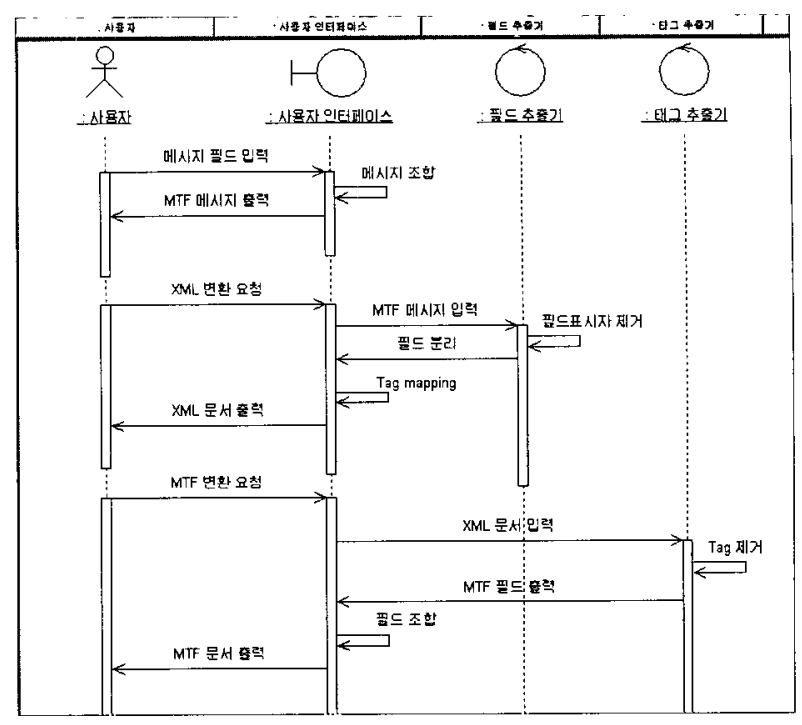

(그림 11) XML-MTF 시스템 처리 절차

필드 추출기 모듈은 인터페이스 모듈로부터 $\mathrm{MTF}$ 메시지 를 입력받으면 $\mathrm{MTF}$ 메시지의 펄드표시자( )를 기준으로 각 필드를 분리한 다음 분리된 필드를 인터패이스 모듈로 보내 는 역할을 수행한다.

태그 추출기 모듈은 인터페이스 모듈로부터 XML 문서를 입력받으면 $\mathrm{XML}$ 문서의 노드(node)를 구분하고, 노드별로 $\mathrm{XML}$ 태그를 제거하여 MTF 메시지의 필드가 되는 데이터 만을 추출하여 인터페이스 모듈로 보내는 역할을 수행한다. 이와 같은 전체적인 시스템 처리 절차가 (그림 11)에 시퀀 스(Sequence) 다이어그램을 이용하여 표시되어 있다.

$\mathrm{XML}-\mathrm{MTF}$ 변환 프로그램의 초기화면은 크게 3 부분으로 구성되어 있다. 메시지 선택화면에서는 사용할 수 있는 $\mathrm{MTF}$ 메시지의 목록이 나타나며, 메시지 폼 입력화면은 선 택한 메시지 Set 별 필드를 입력받기 위한 폼을 제공한다. 결과 시현화면에는 완성된 $\mathrm{MTF}$ 메시지나 $\mathrm{XML}$ 문서를 출 력 한다.

$\mathrm{MTF}$ 메시지를 생성하기 위해서 먼저 선택된 Set에서 각 필드란에 필요한 필드 데이터를 입력하고, “입력" 버튼을 클 릭하면, XML-MTF 변환 프로그램은 각 필드 데이터를 조 합하여 하단의 결과 시현화면에 해당 Set의 MTF 메시지를 출력한다.

출력과 동시에 데이터를 입력했던 필드란이 비워지게 되 므로 같은 Set을 계속해서 입력할 수 있다. 이러한 방법으로 원하는 Set을 지속적으로 선택하여 하나의 메시지를 완성하 게 된다. 필드에 데이터를 입력하여 결과가 출력되는 화면 을 (그림 12)에 나타내었다.

메시지 작성 후 작성된 메시지를 XML 문서로 변환하면 내부적으로 필드 추출기 모듈에 의해 $\mathrm{MTF}$ 메시지를 필드 별로 분리한 다음, 분리된 필드 데이터를 $\mathrm{XML}$ 변환규칙에 따라 미리 지정된 XML 태그를 매핑하여 XML 문서를 생성 한다. 생성된 XML 문서는 메시지 명칭과 동일한 "TACREP. $\mathrm{xml}$ "이라는 파일명으로 프로그램 실행 디렉토리에 저장되 


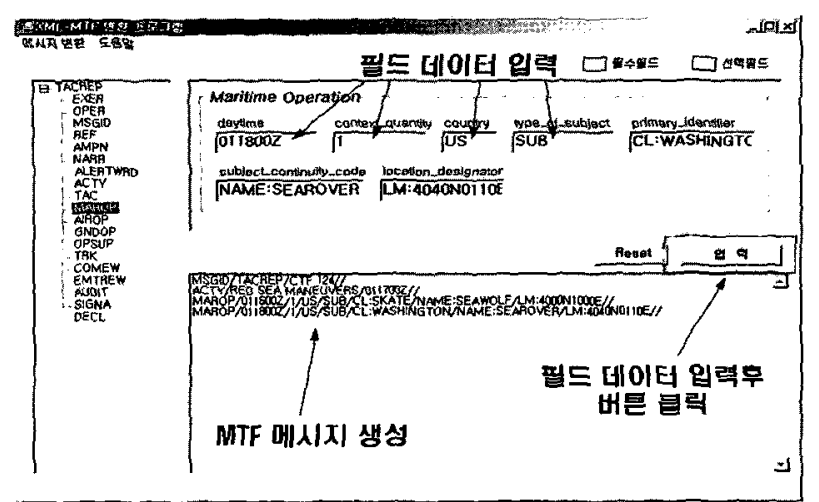

(그림 12) 필드 데이터 입력 및 MTF 메시지 생성

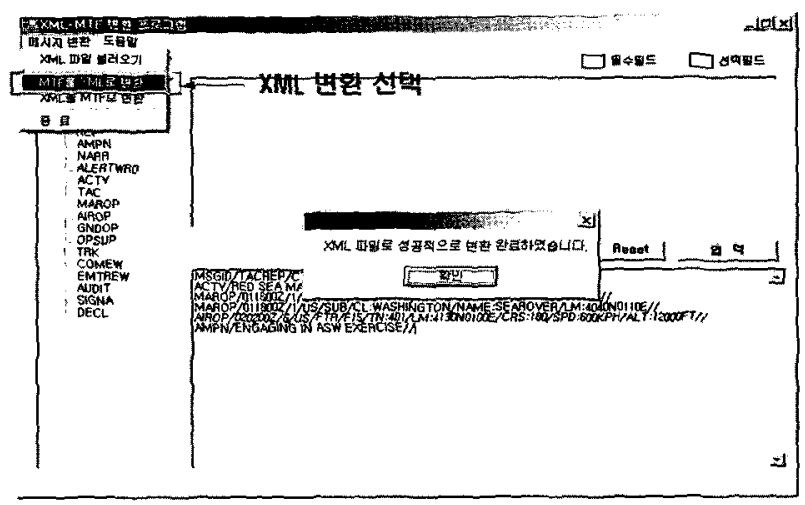

(그림 13) MTF를 XML로 변환

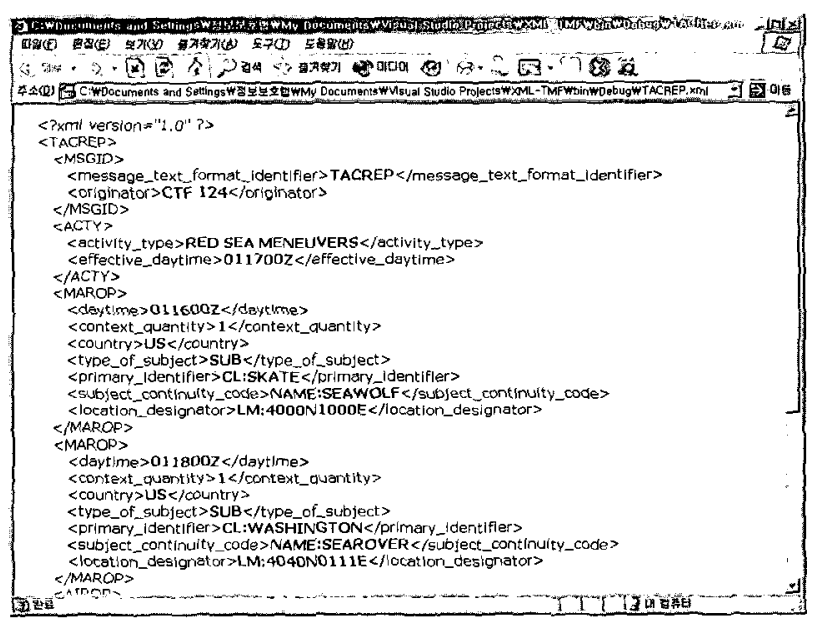

(그림 14) XML 문서로 변환된 MTF 메시지

며, 프로그램은 성공적으로 작업이 완료되었음을 표시한다. $\mathrm{XML}$ 로 변환을 위해 메뉴를 선택하고 변환이 성공적으로 이루어졌음을 알리는 화면을 (그림 13)에 도시하였다.

저장된 XML 파일을 MS Explorer로 불러온 화면을 (그 림 14)에 나타내었다. 그림과 같이 웹 브라우저에서 XML 문 서가 트리구조로 나타나면 이는 XML 스펙에 위배됨이 없이 올바르게 작성된 문서임을 의미한다. 따라서 MTF 매시지가 $\mathrm{XML}$ 문서로 변환이 성공적으로 이루어 젔음을 알 수 있다.

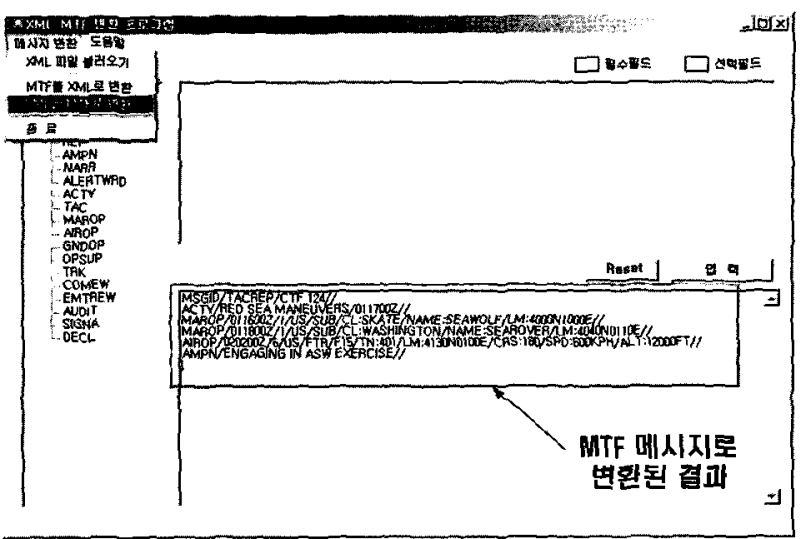

(그림 15) MTF 메시지로 변환된 결과

생성된 XML 파일을 다시 MTF 메시지로 변환하기 위해 변환하고자하는 XML 파일올 선택하면, XML-MTF 변환 프로그램은 내부적으로 태그 추출기 모듈에 의해 XML 파 일을 해석하고, 태그를 제거하여 순수한 필드 데이터만 추 출한다. 그런 다음 MTF 메시지 생성 규칙에 따라 Set과 필 드를 구분하여 다시 MTF 메시지를 구성하여 그 결과를 결 과 시현화면에 출력한다.

이와 같이 XML 문서를 다시 MTF 메시지로 변환된 결 과를 표시한 화면을 (그림 15)에 나타내었다. 처음 생성된 MTF 메시지와 동일함을 알 수 있다.

\section{5. 결 론}

본 논문에서는 CAI 시스템 간 정보를 전달하기 위해 사 용되는 MTF 메시지의 개요, 작성규칙 및 기본적인 구조를 분석하였으며, XML-MTF의 구현 수단인 XML의 개념 및 관련표준, 기본구조 등에 대해서도 고찰하였다. 또한, MTF 메시지를 대상으로 메시지 구조를 분석하고, 분석된 구조를 바탕으로 XML-MTF 변환을 위한 MTF와 XML과의 매핑 규칙을 설계하였으며, 설계한 매팡 규칙을 가지고 메시지 샘쯜을 XML, 문서로 직접 변환해 보았다.

XML-MTF 상호변환 구현을 위해 ROK/US MTF중 TACREP 메시지에 대해 필드별 XML 엘리먼트 정의 및 엘 리먼트 명칭과 속성을 정의하는 스키마 파일을 작성하였으 며, 이를 XML 문서로 자동으로 변환하는 간단한 형태의 프 로그램을 구현해 보았다. 구현된 프로그램에 여러 개의 TACREP 샘플 메시지를 적용하여 테스트한 결과 모두 이상 없이 MTF 메시지와 XML간의 변환을 수행할 수 있었다.

\section{참 고 문 헌}

[1] Andress Tolks, "A Common Framework for Military M\&S and C4I System," SSIW, 2003.

[2] US DoD, "CAI Joint Extensible Markup Language(XML) Message Text format(MTF) Roadmap(JXMR)," 2003. 
[3] Robert Cherinka, "A Case Study using XML to Enhance Information Interoperability," WROX conference, 2001.

[4] Dr. Bob Cherinka, "Using XML-Based Web Services to Enhance Information Interoperability In the Department of Defence," XML Conference 2001, 2001.

[5] Kyle Ray, "USMTF to XML-MTF," DISA, 2003.

[6] US DoD, MIL-STD-6040, “U.S. Message Text Formatting Program Description of U.S. Message Text Formatting Program," 2002.

[7] John C. Schneider, "XML-MTF A technology opportunity to position MTFs for the 21 Century," USMTF Standards Management Committee, 1999.

[8] US DoD, "U.S. Message Text Formatting Program Description," MLL-STD-6040, 2002.

[9] 합참, 사용자 교범, $\mathbf{r}$ 한 - 미 표준전문양식(ROK/US MTF) 연 합상호 연동운영절차(CIOP)」, 1997.

[10] 윤희병, "메시지 포맷을 이용한 체계통합," 제 4회 국방정보화 심포지움, 2003.

[11] M. Altmel, M.J. Franklin, "Efficient Filtering of XML Documents for Selective Dissemination of Information," Proceeding of the 26th VLDB Conference, 2000.
[12] Harry M. Sneed, "Using XML to Integrate Existing Software Systems into the Web," COMPSAC, 2002.

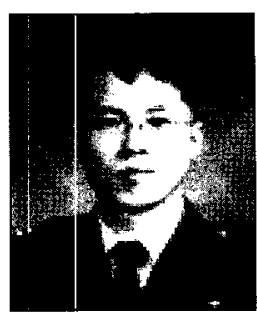

\section{박 인 수}

e-mail : jikimpis@hitel.net

1996년 금오공과대학교 기계설계공학과

(학사)

2004년 국방대학교 전산학(석사)

2005년 현재 전투비행단 무장대대 관심분야 : 인공지능, 전술데이터링크

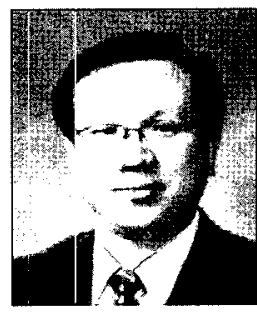

\section{윤 희 병}

e-mail : hbyoon@kndu.ac.kr 1983년 해군사관학교(이학사)

1986년 연세대학교(공학사)

1991년 미국 해군대학원 전산공학(석사)

1998년 미국 Georgia Institute of Technology 전산공학(박사)

2002년 현재 국방대학교 전산정보학과 조교수 관심분야 : 임베디드 소프트웨어, 전술데이터링크, 웹마이닝 